\title{
Impacto do Simples Nacional no Emprego das MPES do Estado de Pernambuco
}

\author{
Joane Alinne Paiva Bendô ${ }^{1}$ | Roberta Moraes Rocha ${ }^{2}$ (D) | Wellington Ribeiro Justo ${ }^{3}$ | Raul \\ da Mota Silveira Neto ${ }^{4}$ \\ ${ }^{1}$ Universidade Federal de Pernambuco, Centro Acadêmico do Agreste. E-mail: joanebendo@gmail.com \\ ${ }^{2}$ Universidade Federal de Pernambuco, Centro Acadêmico do Agreste. E-mail: robertarochape@yahoo.com.br \\ ${ }^{3}$ Universidade Regional do Cariri. E-mail: justowr@yahoo.com.br \\ ${ }^{4}$ Universidade Federal de Pernambuco. E-mail: rau.silveira@uol.com.br
}

\begin{abstract}
RESUMO
Este artigo propõe-se a investigar se o Simples Nacional tem implicado níveis mais elevados de emprego para as MPEs, que são beneficiadas pelo regime de tributação simplificado e pelas alíquotas menores das contribuições e impostos que incidem sobre as empresas no Brasil. Ao focar na empresa, pode-se dizer que a renúncia fiscal gerada pelo Simples se difere das tradicionais políticas de incentivos fiscais regionais adotadas no Brasil. Porém, espera-se que os estados que têm a economia mais dependente das MPEs sejam os mais favorecidos por uma política direcionada a essas empresas. Para tanto, foram utilizados os microdados identificados da base de dados da RAIS-ME (2002 a 2014), a partir dos quais foi possivel estimar modelos de regressão com controles para as características observáveis e não observáveis das firmas e, também, locacionais. O objeto de análise foi uma das principais economias da Região Nordeste, o estado de Pernambuco. Isto porque as MPEs têm uma relativa importância para a geração de emprego e renda no estado, consolidando-se em polos produtivos, especializados em serviços (Médico e Tecnológico) e indústrias/comércio (Têxtil/Confecção). Ademais, trabalhar com uma amostra de empresas que estão expostas a fatores econômicos e fiscais semelhantes minimiza possiveis vieses causados por variáveis omitidas. Os resultados encontrados indicaram que as empresas que estão no Simples Nacional geraram, em média, aproximadamente 19\% mais empregos, quando comparadas com o grupo de controle, sendo esse efeito ainda maior para as empresas que passam mais tempo ininterrupto no Simples. Esses resultados são válidos mesmo após a incorporação de controles fixos e variantes no tempo das empresas e locacionais, sugerindo que a política tem um impacto positivo no mercado de trabalho formal no estado.
\end{abstract}

\section{PALAVRAS-CHAVE}

Micro e pequenas empresas, Simples Nacional, Avaliação de política

\section{Impact of "Simples Nacional" on Employment of SMEs in the State of Pernambuco}

\section{ABSTRACT}

This article aims to investigate whether Simples Nacional has resulted in higher levels of employment for SMEs that benefit from the simplified tax regime and the lower rates of contributions and taxes levied on companies in Brazil. By focusing on the company, it can be said that the tax waiver generated by Simples differs from the traditional regional tax incentive policies adopted in Brazil. However, it is expected that the states that have the economy most dependent on MSEs, will be the most favored by a policy directed to these companies. For that, we used the microdata identified from RAIS-ME (2002 to 2014), from which it was possible to estimate regression models with controls for the observable and unobservable characteristics of the firms and, also, locational ones. The object of analysis was one of the main economies of the Northeast Region, 
the state of Pernambuco, due to the fact that MSEs have a relative importance for the generation of employment and income in the state, consolidating themselves in productive centers, specialized in services (Medical and Technological) and industrial/trade (Textile/Clothing). Furthermore, working with a sample of companies that are exposed to similar economic and fiscal factors minimizes possible biases caused by omitted variables. The results found indicated that the companies that are in Simples Nacional generated, on average, approximately 19\% more employment, when compared to the control group, being this effect even greater for companies that spend more uninterrupted time in Simples. These results are valid even after the incorporation of fixed and time-based controls of companies and locations, suggesting that the policy has a positive impact on the formal labor market in the state.

\section{KEYWORDS}

Micro and small enterprises, Simples Nacional, Policy evaluation

\section{Introdução}

As micro e pequenas empresas (MPEs) ${ }^{1}$ formais têm uma significativa importância para a economia dos países em desenvolvimento e, em especial, para países como o Brasil, que tem um regime tributário de elevada complexidade e uma legislação trabalhista que dificulta a contratação de trabalhadores formais (Leal Brito e Alcantara, 2012). De acordo com o relatório do Bank (2013), o Brasil ocupa o $124^{\circ}$ lugar no critério de dificuldade para abrir uma empresa ${ }^{2}$. Segundo dados da Relação Anual de Informações Sociais (RAIS) do Ministério da Economia (ME) do ano de 2014, a maioria dos estabelecimentos formais do Brasil era composta por MPEs (93\%), responsáveis por 1/3 do emprego formal do país. Para as Regiões menos desenvolvidas, com elevadas taxas de desemprego e informalidade, as MPEs têm uma relevância ainda maior para a economia, por impactar positivamente a receita tributária municipal e o emprego local. Ademais, além desse impacto direto, evidências empíricas apontam para a importância das MPEs na geração de externalidades produtivas favoráveis à formação de complexos industriais, as quais são as mais beneficiadas pelas economias de aglomeração advindas da especialização produtiva (Rosenthal e Strange, 2010). Neste sentido, citam-se como exemplos os distritos industriais italianos, o cluster de alta tecnologia na região do Vale do Silício nos Estados Unidos, e os Arranjos Produtivos Locais no Brasil ${ }^{3}$ (Ellison e Glaeser, 1997; Souza Filho, 2009), todos com uma característica em comum: formados por MPEs que são beneficiadas pela concentração de mão de obra especializada (laborpooling).

\footnotetext{
${ }^{1}$ Segundo o Serviço Brasileiro de apoio às Micro e Pequenas Empresas (SEBRAE), as micro e pequenas indústrias possuem até 100 empregados (SEBRAE, 2013).

${ }^{2}$ Para maiores informações, consultar https://portugues.doingbusiness.org/pt/rankings.

${ }^{3}$ No Brasil, a ideia de "Arranjo Produtivo Local (APL)" é utilizada tanto por acadêmicos quanto pelos órgãos de fomento, para identificar os setores prioritários para as políticas públicas e privadas que têm o objetivo de promover as aglomerações produtivas em todo o país. Para mais informações, consultar https://www.bndes.gov.br/wps/portal/site/home/conhecimento/pesquisaedados/estudos/bndesfep/pesquisa e http://www.redesist.ie.ufrj.br/atividades/mapa-de-apls.
} 
Para Pernambuco, por exemplo, estado localizado na Região Nordeste - região com maior percentual de benefícios de programas sociais do Governo Federal, proporcionalmente à população ${ }^{4}$, os dados da RAIS (2014) indicaram que $42 \%$ do emprego formal do estado foi gerado pelas $\mathrm{MPEs}^{5}$. Essas empresas representavam aproximadamente $90 \%$ do total de empresas formais do estado (mais de 100 mil empresas). Já considerando a informalidade, a pesquisa "Economia Informal Urbana" do Instituto Brasileiro de Geografia e Estatística (IBGE), do ano de 2003, apontou que, no estado de Pernambuco, 92,7\% das empresas informais possuíam menos de 3 pessoas ocupadas (número similar ao do estado de São Paulo no mesmo ano, que foi de 92,8\%). Associa-se a essas estatísticas o fato de o estado de Pernambuco ter tido, no ano de 2014 , uma taxa de desocupação $(4,7 \%)$ acima da média nacional $(4,4 \%)^{6}$. Defende-se, assim, que políticas que objetivem incentivar o trabalhador, que está desocupado, a empreender e formalizar a sua atividade produtiva venham a ter um impacto positivo na economia do estado.

Contudo, com a complexa legislação e com a excessiva burocracia do país, as MPEs enfrentam obstáculos e custos relativos maiores para se formalizarem, comparadas às demais empresas (gastos iniciais com registro social, alvará sanitário, alvará de estabelecimento, alvará especial conforme o estabelecimento, notas fiscais, entre outros). Além disso, segundo ranking do Bank (2013), a abertura de uma empresa no país pode demorar até 79 dias e a carga tributária paga pelas empresas representam, em média, 69,3\% do seu lucro. Essas dificuldades fazem com que o investidor pondere entre os custos financeiros e os benefícios de formalizar a sua empresa. Por outro lado, empresas formalizadas possuem maior acesso a crédito, possibilidade de vender/prestar serviço para grandes empresas, maior segurança em contratações, facilidade de acesso à matéria-prima, direito à Previdência Social, entre outras vantagens.

Diante desses problemas e considerando a importância das micro e pequenas empresas para o país, foi criado no Brasil, no ano de 1997, o Sistema Integrado de Pagamento de Impostos e Contribuições das Microempresas e das Empresas de Pequeno Porte (SIMPLES ou Simples Federal). Buscando simplificar ainda mais o sistema de tributação voltado às MPEs e aumentar a limite da margem de lucro, no ano de 2007, o Simples Federal foi modificado para o Regime Especial Unificado de Arrecadação de Tributos e Contribuições devidos pelas Microempresas e Empresas de Pequeno Porte (Simples Nacional). Esse regime visa ao tratamento diferenciado, à simplificação e ao incentivo fiscal às MPEs, relativo às contribuições e aos impostos, além de apoiar sua inovação, certificação e formalização. Nesse regime, são consideradas como microem-

\footnotetext{
${ }^{4}$ Considerando todos os benefícios sociais do Governo Federal, inclusive o auxílio emergencial da COVID-19, tem-se a região Nordeste em primeiro lugar com uma relação de 55\% do número de benefícios ponderado pela população, seguida das regiões Norte (49\%); Centro-Oeste (46\%); Sudeste (39\%); e Sul (29\%). Disponivel em: http://www.portaltransparencia.gov.br/beneficios.

${ }^{5}$ Adotando-se como micro e pequena empresa empreendimentos com até 100 empregados, segundo a Classificação dos Estabelecimentos Segundo Porte para o setor da indústria (SEBRAE, 2013).

${ }^{6}$ De acordo com os dados do primeiro semestre do ano de 2014 da Pesquisa Nacional por Amostra de Domicílio Contínua (PNAD Continua) do Instituto Brasileiro de Geografia e Estatística (IBGE).
} 
presas e empresas de pequeno porte aquelas que têm receita bruta anual de até $\mathrm{R} \$$ 4,8 milhões (quatro milhões e oitocentos mil reais).

Pode-se conjecturar, portanto, que, ao focar na empresa, nas MPES, independente da sua localização, o Simples Nacional apresenta um avanço nas políticas regionais de incentivos fiscais adotadas no Brasil, o que, consequentemente, termina beneficiando em maior magnitude as economias mais dependentes das MPES.

Neste sentido, estima-se que, com a aplicação do Simples Nacional, em média, mais de 9,5\% do total de alíquotas das MPEs do setor industrial podem ser reduzidas ${ }^{7}$. Assim, com o Simples, o governo deixa de arrecadar quantias consideráveis, sendo a principal renúncia fiscal e previdenciária do país. De acordo com a projeção dos principais gastos tributários no país, o Simples Nacional chegou a responder por $27,51 \%$ do gasto tributário do país no ano de 2016, o que representa mais de 74 bilhões de reais ${ }^{8}$. Devido à elevada renúncia fiscal associada ao Simples Nacional, recurso esse que poderia ser aplicado em setores como educação e saúde, é de extrema importância avaliar o impacto social e econômico da política.

Deste modo, as evidências empíricas de prévios estudos que buscaram avaliar o Simples (considerando diferentes unidades geográficas e métodos) indicaram que a política: $i$. favorece uma maior contratação de trabalhadores (Araújo, 2008; Lima Neto, 2009; Paes, 2015; Conceição et al., 2016; Franco et al., 2017); ii. contribui para redução do fechamento dos postos de trabalho (Corseuil e Moura, 2011); iii. incentiva a formalização das empresas e a reativação das empresas inativas (Kalume et al., 2012); e $i v$. reduz a mortalidade das empresas (Conceição et al., 2016). Além disso, corroborando os indícios dos efeitos positivos do Simples para a economia do País, Paes (2015); Franco et al. (2017) evidenciaram que as empresas optantes pelo Simples, em média, remuneram melhor os seus trabalhadores, quando comparadas com as empresas que não estão nesse regime tributário.

Esses estudos sugerem que políticas de desburocratização e desoneração fiscal direcionadas às MPEs podem ter um impacto positivo na economia, seja através do incentivo a formalização ou da redução dos custos operacionais, o que pode levar a um aumento na contração de trabalhadores ou nos salários. Contudo, uma limitação que emerge de estudo para diferentes economias estaduais refere-se à dificuldade de isolar o efeito do Simples de outras políticas estaduais que podem atuar em conjunto ou não ao Simples, na geração do emprego e renda. Outra questão diz respeito às diferenças entre o grau de informalidade das economias, as quais devem responder de forma diferenciada a incentivos fiscais para formalização.

Buscando contribuir para essa literatura, a presente pesquisa investiga se a implementação do Simples Nacional implicou algum impacto positivo no número de trabalhadores contratados pelas empresas que fizeram a opção por esse regime tributário.

\footnotetext{
${ }^{7}$ As alíquotas para os demais setores encontram-se nos Anexos I e III a VI da Lei Complementar № 123, de 14 de dezembro de 2006. Disponivel em: http://www.planalto.gov.br.

${ }^{8}$ Dados da Receita Federal, disponivel em: https://receita.economia.gov.br/.
} 
Espera-se que esses benefícios fiscais aumentem os fluxos de caixa das empresas fazendo com que invistam mais na ampliação da produção e dos insumos ou mesmo na formalização da mão de obra empregada. Para testar essa hipótese, modelos de regressão são estimados a partir dos microdados identificados da RAIS-ME, os quais permitem o acompanhamento longitudinal das empresas por um identificador único, o CNPJ (Cadastro Nacional de Pessoa Jurídica). Na ausência de informação sobre a receita das empresas na base de dados, para filtrar as elegiveis ao Simples Nacional, foi feito um recorte com base no número de pessoas ocupadas. A amostra foi dividida em dois grupos: grupo de tratamento, com aquelas que aderiram ao Simples a partir do ano de 2007 e grupo de controle, composto pelas empresas que não foram beneficiadas pelo Simples no período compreendido entre 2002 e 2014. Assim, controlada por um conjunto de características observáveis das empresas e locacionais, além do efeito fixo da empresa, locacional e de tempo, pode-se estimar a diferença entre o emprego gerado pelo grupo de empresas tratadas e não tratadas.

A escolha da unidade geográfica para a análise, o estado de Pernambuco, respaldase em três principais justificativas. Primeira: como é um estado com uma elevada taxa de informalidade e participação das micro e pequenas empresas na sua economia, estima-se que políticas como essa sejam relativamente mais importantes para a geração de emprego e renda, quando comparadas com economias mais formalizadas e desenvolvidas. De acordo com a PNAD contínua do ano de 2018, estima-se que o percentual de trabalhadores ocupados em atividades informais seja de 51,6\% no estado, enquanto a média nacional é de $41,5 \%{ }^{9}$. Outra questão refere-se à importância de isolar a influência de outras políticas fiscais estaduais na variável de impacto, o emprego pode ser contornado ao se realizar o estudo para uma unidade da federação em específico. Ademais, o "emprego" foi escolhido como a variável de resultado para a análise porque é considerado um importante termômetro das economias locais (Bartik, 1991): por estar diretamente relacionado ao bem-estar dos consumidores; por ser uma variável de fácil mensuração e menos suscetivel a erros nos registros da base; e pela compatibilidade de comparação em relação a outros estudos. Por último, destaca-se que, no estado, há pelo menos três importantes polos produtivos compostos por MPEs que, quando concentradas, são beneficiadas pelas economias de escala geradas externamente às firmas. O polo têxtil/confecção, localizado no interior do estado, no agreste pernambucano, surgiu como uma forma alternativa de geração de emprego e renda na região, em reposta às dificuldades econômicas advindas de uma região de clima semiárido (SEBRAE, 2012; Rocha et al., 2015; Andrade et al., 2016). Além disso, outros dois polos produtivos estão na Região Metropolitana do Recife e têm atividades interrelacionadas: o polo de informática (Rocha et al., 2009), composto por empresas de software e serviços de informática; e o polo médico (Fernandes e Lima, 2006).

A próxima seção apresenta de forma suscinta as políticas de incentivos fiscais às

\footnotetext{
${ }^{9}$ Fonte: IBGE, Pesquisa Nacional por Amostra de Domicílios Contínua, 2018.
} 
MPEs, com destaque para o Simples. Nas duas seções subsequentes, são descritos os modelos empíricos (terceira seção) e os dados (quarta seção). A discussão dos resultados é objeto da quinta seção e as conclusões estão reportadas na sexta seção.

\section{Politicas fiscais direcionadas às micro e pequenas empre-} sas

As políticas fiscais de incentivos ao aumento da produção e da produtividade das empresas, que têm como objetivo estimular a formalização, a geração de emprego e de renda, através de benefícios financeiros aos produtores, subdividem-se, sobretudo, em três principais grupos: $i$. aquelas que relacionam as isenções fiscais à localização da empresa/produtor, com o objetivo de estimular a atividade produtiva de localidades menos industrializadas; $i$. as políticas setoriais, que visam ao desenvolvimento de algum setor produtivo da economia; e iii. os incentivos fiscais e linhas de créditos, com taxas de juros especiais, que são direcionadas às MPEs, independente da sua localização.

Evidências empíricas têm mostrado, tanto para o Brasil (Lyra et al., 1995) quanto para os demais países (Thomsen et al., 2013; Chaurey, 2017; Giroud e Rauh, 2019), que as políticas regionais de incentivos fiscais atuam influenciando na localização das empresas, implicando um impacto positivo no emprego e na renda daquelas regiões que ofertam melhores condições econômicas e benefícios fiscais.

Evidências internacionais de políticas direcionada às MPEs foram analisadas por Puga (2000) para três países: Estados Unidos (EUA), Itália e Taiwan. Nos EUA, existem vários programas de apoio às MPEs, por exemplo o Small Business Innovation Research Programme (SBIR), que visa estimular a inovação no setor de Pesquisa e Desenvolvimento (P\&D). Há também o Service Corps of Retired Executives (SCORE), com serviço especial de consultoria às empresas de pequeno porte, e as Business Incubators (Incubadoras), que disponibilizam espaço físico e treinamento gerencial às novas empresas por um período de dois a três anos. Na Itália, com o intuito de combater a desigualdade regional entre o Norte e o Sul do país, o governo oferta crédito a nível federal, pelo Banco Europeu de Investimentos e pelo Centrale (banco que foi criado para oferecer empréstimos para as empresas interessadas em exportação), para linhas de crédito direcionado às micro, pequenas e médias empresas. Em Taiwan, há programas de apoio às MPEs, desde a década de 1970, com a criação do Small and Medium Business Credit Guarantee Fund, responsável por apoiar e disponibilizar crédito às MPEs.

Na França, há três principais tipos de regimes tributários diferenciados, que preveem simplificação tributária e incentivo fiscal para os autônomos empreendedores, os quais dependem do tipo de atividade e do nível de receita das empresas (Aghion et al., 2017). Aghion et al. (2017) avaliaram as mudanças desses regimes entre o período de 1994 e 2012 e evidenciaram que uma maior simplificação tributária gera um 
impacto positivo na formalização ou na criação de empresas de menor porte.

Entre as políticas direcionadas às MPEs no Brasil, a presente pesquisa tem como objeto de análise o Simples Nacional e propõe-se a mensurar quantitativamente o impacto do Regime de Tributação na geração de emprego no estado de Pernambuco.

\subsection{Simples}

O Simples Federal foi criado pela Lei no 9.317 de 5 de dezembro de 1996 e implantado no ano de 1997 (Brasil, 1996, 2016). A lei do Simples Federal foi revogada pela Lei Complementar no 123 de 14 de dezembro de 2006 para o Regime Especial Unificado de Arrecadação de Tributos e Contribuições devidos pelas Microempresas e Empresas de Pequeno Porte (Simples Nacional). O Simples Nacional passou a vigorar no ano de 2007, com duas principais mudanças. A inclusão de mais dois tributos, aos cinco já incorporados no Simples Federal: o Imposto sobre Operações Relativas à Circulação de Mercadorias e sobre Prestações de Serviços de Transporte Interestadual e Intermunicipal e de Comunicação (ICMS) e o Imposto sobre Serviços de Gualquer Natureza (ISS) ${ }^{10}$. O Simples Nacional também elevou o teto da receita bruta, que torna as empresas elegiveis: passou a ser microempresa a empresa que tem receita bruta igual ou inferior a R\$ 360 mil (no Simples Federal era R\$ 240 mil) e empresas de pequeno porte são aquelas que têm receita bruta superior a R\$360 mil e igual ou inferior a R\$ 4,8 milhões (no Simples Federal era R\$ 240 mil e igual ou inferior a R\$ 2,4 milhões). Ambas as mudanças implicaram aumento do número das empresas elegiveis ao sistema de tributação.

O valor devido mensalmente pela empresa que optou pelo Simples Nacional é determinado com base na aplicação de alíquotas efetivas, calculadas a partir de alíquotas nominais constantes, utilizando a receita bruta acumulada nos 12 meses anteriores aos do período de apuração. Dessa forma, o regime do Simples Nacional, em média, pode reduzir em torno de 9\% do total das alíquotas das MPEs do setor de comércio, $9,5 \%$ do setor da indústria, e pode chegar a quase $21 \%$, dependendo a qual área do setor de serviços pertence a MPE. No Guadro 1, no anexo A, encontram-se essas alíquotas para a indústria ${ }^{11}$. É válido ressaltar que, apesar de alíquotas constantes para cada setor da economia, os reais valores reduzidos não são constantes de estado para estado, já que há diferenças entre as parcelas do ICMS, por exemplo.

\footnotetext{
${ }^{10}$ Os impostos e as contribuições que já existiam no Simples Federal permaneceram no Simples Nacional, a saber: Imposto de Renda das Pessoas Jurídicas (IRPJ), Contribuição para os Programas de Integração Social e de Formação do Patrimônio do Servidor Público (PIS/PASEP), Contribuição Social sobre o Lucro Líquido (CSLL), Contribuição para Financiamento da Seguridade Social (COFINS), Imposto sobre Produtos Industrializados (IPI) e Contribuições para Seguridade Social (a cargo da pessoa jurídica).

${ }^{11}$ As aliquotas para os demais setores encontram-se nos Anexos I e III a VI da Lei Complementar № 123, de 14 de dezembro de 2006. Disponivel em: http://www.planalto.gov.br.
} 


\subsection{Prévias evidências empiricas sobre a importância do Simples}

As políticas públicas que implicam redução da receita do governo ou aumento dos gastos públicos devem ser monitoradas e avaliadas continuamente. No caso do Simples, segundo a PLOA (Projeto de Lei Orçamentária Anual) do ano de 2020, a previsão é de que seja a principal fonte de gastos tributários do país, representado quase $1 / 4$ de todos os gastos tributários. Por outro lado, políticas como essa são justificadas quando há efetividade de seus objetivos, ao incentivar a formalização e a abertura de empresas, ao impactar positivamente a geração de emprego e a massa salarial, gerando efeitos multiplicadores de renda para toda a economia. Com esse propósito de pesquisa, prévios estudos já foram realizados para o Brasil, com o objetivo de avaliar o impacto do Simples em indicadores da atividade produtiva.

Araújo (2008), a partir dos dados da RAIS para o período de 1985 a 2005, investiga se o Simples impactou positivamente o emprego formal gerado pelas empresas da Região Nordeste, que foram beneficiadas por esse regime de tributação (grupo de tratamento). O autor adotou como grupo de controle as empresas de médio e grande porte. Os resultados da pesquisa indicam consistência do Simples para a geração de emprego pelas indústrias da região. Com o mesmo propósito de pesquisa e base de dados (anos 1995, 2000, 2005), Lima Neto (2009) expandiu a análise para as microrregiões do Brasil, para a indústria têxtil e de confecção e obteve indicações de que, após a implementação do Simples, as MPEs da indústria passaram a empregar mais trabalhadores. Porém, dada a heterogeneidade da economia das microrregiões do país, é possível que outras políticas estaduais ou choques aleatórios específicos impliquem vieses nas estimações.

Corseuil e Moura (2011) fizeram importantes contribuições para a literatura ao investigarem a influência do Simples Federal na probabilidade de sobrevivência das firmas. A partir dos dados da PIA-IBGE, para o período de 1996 e 1999, os autores aplicaram o método diferença-diferença: as empresas optantes pelo Simples compuseram o grupo de tratamento e as empresas com faturamento próximo ao limite da elegibilidade ao programa formaram o grupo de controle. Os resultados dos autores indicaram que a criação do Simples contribuiu para aumentar os postos de trabalho na indústria e para evitar o fechamento delas. Mas, concluíram que a mudança do critério de elegibilidade, no ano de 1999, não influenciou no nível de emprego das empresas. Esses resultados sugerem que a redução da burocracia tributária implica benefícios para as MPEs, mas a redução da carga tributária deve ser mais bem avaliada.

Na literatura, identificam-se dois estudos para o período pós-2006, quando houve uma desburocratização e ampliação do grupo de empresas elegiveis ao Simples Federal. Paes (2015), a partir de uma análise exploratória dos dados do Guia de Recolhimento do Fundo de Garantia (FGTS) e de Informações à Previdência Social (GFIP) e da RAIS, comparou o nível de emprego gerado pelas empresas optantes pelo Simples Nacional e pelas empresas não beneficiadas pelo regime tributário. Entre os prin- 
cipais resultados, o autor destaca que o número de empresas que estão no regime cresceu a uma taxa superior às demais empresas e que elas geraram relativamente mais empregos. Embora o mencionado estudo seja de caráter descritivo, salienta-se a sua contribuição à literatura, por utilizar uma base de dados ainda não explorada nesta temática de pesquisa.

Buscando contornar essas limitações, Franco et al. (2017) inovaram ao aplicarem o método de regressão descontínua para estimar o impacto do Simples Nacional nos custos operacionais, no emprego e no salário médio pago pelas indústrias que têm mais de 30 pessoas ocupadas e que estão no cadastro da Pesquisa Industrial Anual (PIA) do IBGE nos anos de 2000 a 2012. Os autores captaram a descontinuidade do modelo através do valor da receita bruta das empresas que ficaram na margem de se tornarem elegiveis ao Simples. Os resultados indicaram um efeito positivo do Simples sobre o custo operacional (23\%), os salários do pessoal ocupado $(25,18 \%)$ e o emprego $(21,5 \%)$.

Os referidos estudos apresentam relevantes contribuições para a avaliação do Simples, porém ainda há lacunas que precisam ser exploradas, principalmente no que diz respeito à escolha do grupo de tratamento e controle. Além disso, evidências empíricas da importância das MPEs para a geração de emprego e até mesmo da importância do Simples, com ênfase no estado de Pernambuco, ainda são inexistentes. O presente trabalho também contribuiu para o tema da avaliação da política, ao utilizar uma base de dados, os microdados identificados da RAIS, que tornam possivel a comparação da variável de resultado, o emprego, entre as MPEs optantes e não optantes pelo Simples, as quais estão expostas por condições locais (econômicas, tributárias, etc.) semelhantes, por estarem sediadas no mesmo estado.

\section{Modelo empirico}

A análise a seguir baseia-se na estimação de três modelos, que têm como objetivo mensurar a diferença entre o nível de emprego do grupo de empresas optantes pelo Simples Nacional (grupo de tratamento) e do grupo de empresas que não estão nesse regime de tributação (grupo de controle), após a lei que instituiu o Simples Nacional (ano de 2006).

A estratégia empírica do modelo 1 compreendeu o acompanhamento dos estabelecimentos da amostra ao longo do período de 2002 a 2014, formando uma base em estrutura de painel, a partir da qual foi possivel a estimação com a incorporação de controles para as características observáveis e não observáveis dos estabelecimentos, além dos locacionais. Como o regime de tributação, o Simples Federal foi instituído no ano de 1997 e houve mudanças significativas no ano de 2007 (ano de implementação), optou-se por avaliar apenas o Simples Nacional, retirando da amostra as empresas que eram beneficiadas pelo Simples Federal. Esse corte tornou-se necessário para a homogeneização da amostra, no que diz respeito ao início e ao tempo de exposição 
da intervenção, além de selecionar as empresas de uma mesma geração, com anos de abertura/formalização semelhantes. Adicionalmente, dada a falta de informação acerca da receita das empresas, foi considerada na pesquisa uma amostra de empresas com até 99 empregados (MPEs). Após todos os filtros, a amostra considerada para a estimação do modelo (1) ainda totalizou: 6.174 MPEs, no grupo de tratamento; e 172.956 MPEs, no grupo de controle. Mais detalhes sobre a amostra de empresas estão descritos na seção dos dados.

A forma geral do modelo (1) é descrita pela equação a seguir:

$$
\ln \left(V_{i j t}\right)=\mu_{0}+\mu_{1} I N D S N_{i j t}+X_{i j t} \mu_{2}+Z_{j t} \mu_{3}+\eta_{i}+z_{j}+\gamma_{t}+\varepsilon_{i j t}
$$

em que $\ln \left(V_{i j t}\right)$ é a variável dependente do modelo, logaritmo natural da quantidade de vínculos ativos da empresa $i$ no ano $t$; INDSN $N_{i j t}$ é uma variável dummy que assume 1 no caso da empresa $i$ ter optado pelo Simples Nacional no ano t ( 0 caso contrário); $X_{i j t}$ representa as variáveis controles individuais das empresas; $Z_{j t}$ são controles locacionais; $\eta_{i}$ é a variável de efeito fixo das empresas; $z_{j}$ capta o efeito fixo regional; $\gamma_{t}$ é o efeito fixo de tempo; e $\varepsilon_{i j t}$ é o termo de erro.

O principal parâmetro de interesse para a análise é $\mu_{1}$, que está associado ao indicador da política ( $I N D S N_{i j t}$ ), a partir do qual pode-se comparar o número de vínculos empregatícios formais das empresas que estão no Simples Nacional (Grupo de Tratamento) com o das empresas que não estão nesse regime de tributação. Deste modo, se o coeficiente da variável $I N D S N_{i j t}$ apresentar o sinal positivo e estaticamente significativo até $5 \%$, pode-se inferir que políticas como o Simples, que buscam a desburocratização e os incentivos fiscais às micro e pequenas empresas, devem ter, em média, um efeito positivo no nível de emprego das empresas beneficiadas.

Adicionalmente, um segundo modelo foi estimado para captar a influência do tempo de exposição no Simples Nacional na variável de resultado. Para tanto, foi considerada a mesma amostra de empresas do modelo (1), com algumas adaptações da Equação (1). Para este objetivo, apresenta-se a equação do modelo (2):

$$
\ln \left(V_{i j t}\right)=\mu_{0}+\sum_{t} \mu_{1 t} T E M P S N_{i j t}+X_{i j t} \mu_{2}+Z_{j t} \mu_{3}+\eta_{i}+z_{j}+\gamma_{t}+\varepsilon_{i j t}
$$

a única mudança do modelo (2), em relação ao modelo (1), é na variável do indicador do tratamento, TEMPSN $N_{i j t}$, que agora é composto por variáveis dummies que indicam o tempo em anos que a empresa está no Simples Nacional. Portanto, espera-se que, à medida que aumente o tempo de exposição da empresa ao Simples, também se tenha uma elevação no número do emprego formal da empresa.

A título de comparação, um terceiro modelo também foi estimado a partir de uma amostra restrita, em que foram mantidas no grupo de tratamento apenas as empresas 
que permaneceram no Simples Nacional, durante os oito anos consecutivos da política (372 MPEs), e no grupo de controle (155.118 MPEs) as MPEs que nunca aderiram ao Simples (Federal ou Nacional).

\section{Dados}

A pesquisa foi realizada a partir de uma base de dados oficial do Ministério da Economia (ME), os microdados identificados da Relação Anual de Informações Sociais (RAIS), que disponibiliza informações da população de estabelecimentos formais do país. Destaca-se, porém, que no período considerado na pesquisa, entre 2002 e 2014, o órgão responsável pela base era o Ministério do Trabalho. O período escolhido para a análise se justifica pela disponibilidade dos microdados identificados da RAIS, no formato exigido para a pesquisa, que está disponivel a partir do ano de 2002. Além disso, o ano de 2014 também marcou o final de um período de estabilidade econômica e crescimento do país. Como o propósito da pesquisa é isolar o efeito do Simples Nacional no emprego, acredita-se que outros choques exógenos poderiam contaminar os resultados. Ademais, acredita-se que um período de treze anos, que contempla cinco anos anteriores à implementação da intervenção e oito pós-intervenção, seja suficiente para avaliar algum resultado da política.

Como a base de dados não possui informações sobre a receita bruta (o que possibilitaria estratificar as MPEs de acordo com as definições do Simples Nacional), o que seria ideal para selecionar o grupo de tratamento, considerou-se como MPEs as empresas que possuem até 99 empregados $^{12}$. Segundo dados da PIA, relativos ao ano de 2007, as empresas que possuem entre 5 e 99 empregados têm lucro médio de $\mathrm{R} \$ 224.738,00^{13}$, valor abaixo do limite que o Simples Nacional considera para a empresa ser elegivel ao regime de tributação diferenciado. Porém, cabe considerar a possibilidade de haver empresas que possuem até 99 funcionários e que tenham lucros acima do teto considerado pelo Simples Nacional, mais compatível com as empresas intensivas em tecnologia. Para minimizar possiveis vieses advindos da seleção da amostra, foram incluídos nos modelos controles setoriais. O recorte geográfico, como já justificado, foi o estado de Pernambuco.

As variáveis consideradas nas estimações dos modelos empíricos estão descritas no Quadro 1. Com relação às variáveis controles, foram consideradas nas estimações todas as informações disponiveis na base da RAIS, que não são muitas, que são correlacionadas com o nivel de emprego das empresas.

\footnotetext{
${ }^{12}$ O SEBRAE define como micro e pequena empresa do setor industrial, utilizado como base para a análise, aquelas que têm até 99 empregados.

${ }^{13}$ Considerando a receita líquida de vendas menos os custos e as despesas.
} 
Quadro 1. Descrição das variáveis

\begin{tabular}{|c|c|c|c|}
\hline Variável & Descrição & Ano & Fonte \\
\hline \multicolumn{4}{|c|}{ Variável dependente } \\
\hline$V_{i j t}$ & $\begin{array}{l}\text { Quantidade de vínculos empregatícios } \\
\text { de cada MPE } i \text {, em cada ano } t \text {. }\end{array}$ & $2002-2014$ & Microdados RAIS \\
\hline \multicolumn{4}{|c|}{ Variáveis da política (Simples) } \\
\hline$I N D S N_{i j t}$ & $\begin{array}{l}\text { Dummy que assume o valor } 1 \text { caso a } \\
\text { MPE } i \text { tenha optado pelo Simples } \\
\text { Nacional no ano } t \text {. }\end{array}$ & $2002-2014$ & Microdados RAIS \\
\hline$T E M P S N_{i j t}$ & $\begin{array}{l}\text { Conjunto de dummies que classificam } \\
\text { a quantidade de anos, } t \text {, que a } \\
\text { MPE } i \text { optou pelo Simples Nacional } \\
\text { continuamente. }\end{array}$ & $2002-2014$ & Microdados RAIS \\
\hline$P O S T_{t}$ & $\begin{array}{l}\text { Conjunto de dummies que assumem } 1 \\
\text { para cada um dos anos posteriores } \\
\text { à introdução do Simples Nacional e } \\
0 \text { nos anos anteriores à política. }\end{array}$ & $2002-2014$ & Microdados RAIS \\
\hline$I N D S N T_{i j}$ & $\begin{array}{l}\text { Dummy que assume o valor } 1 \text { caso } \\
\text { a MPE } i \text { tenha optado pelo } \\
\text { Simples Nacional durante todo } \\
\text { o período pós-política (afetada } \\
\text { pelo Simples Nacional). }\end{array}$ & $2002-2014$ & Microdados RAIS \\
\hline \multicolumn{4}{|c|}{ Variáveis de controle } \\
\hline Divisão & $\begin{array}{l}\text { Conjunto de dummies que classificam } \\
\text { a divisão CNAE } 95 \text { de cada empresa. }\end{array}$ & $2002-2014$ & Microdados RAIS \\
\hline IndTrans & $\begin{array}{l}\text { Dummy que assume o valor } 1 \text { caso } \\
\text { a empresa faça parte da seção } \\
\text { CNAE } 95 \text { Indústria da } \\
\text { Transformação e } 0 \text { caso contrário. }\end{array}$ & $2002-2014$ & Microdados RAIS \\
\hline Estrangeira & $\begin{array}{l}\text { Dummy que assume o valor } 1 \\
\text { caso a empresa tenha sido } \\
\text { considerada estrangeira (com } \\
\text { fins lucrativos) e } 0 \text { caso contrário. }\end{array}$ & $2002-2014$ & Microdados RAIS \\
\hline Privada & $\begin{array}{l}\text { Dummy que assume o valor } 1 \\
\text { caso a empresa tenha sido } \\
\text { considerada de natureza jurídica } \\
\text { privada e } 0 \text { caso contrário. }\end{array}$ & $2002-2014$ & Microdados RAIS \\
\hline DensDemogr & $\begin{array}{l}\text { Densidade demográfica (número } \\
\text { de habitantes dividido pela área) } \\
\text { do município de cada empresa por ano. }\end{array}$ & $2002-2014$ & IBGE \\
\hline EmpHab & $\begin{array}{l}\text { Número de empregos por habitantes } \\
\text { por município por ano. }\end{array}$ & $2002-2014$ & Microdados RAIS e IBGE \\
\hline Microrregião & $\begin{array}{l}\text { Conjunto de dummies que } \\
\text { classificam as microrregiões } \\
\text { onde se encontram cada uma } \\
\text { das empresas. }\end{array}$ & $2002-2014$ & IBGE \\
\hline SalárioMédio & $\begin{array}{l}\text { Salário médio por município } \\
\text { por ano (valores deflacionados } \\
\text { em relação a dezembro de 2002). }\end{array}$ & $2002-2014$ & Microdados RAIS \\
\hline
\end{tabular}


Algumas empresas possuem o mesmo CNPJ e diferentes Matrículas CEI (Cadastro Específico do Instituto Nacional do Seguro Social). Essa Matrícula é concedida às empresas com atividades "temporárias" que estão vinculadas ao CNPJ da matriz. Isso ocorre, principalmente, na área da construção civil (o indivíduo recebe uma matrícula CEI por obra, por exemplo). Nesse trabalho, excluíram-se da amostra as empresas que possuíam Matrícula CEI (1.156 empresas). Ou seja, foram consideradas na amostra apenas as empresas matrizes e filiais que têm CNPJ próprio. Além disso, 27 empresas com informações imprecisas quanto ao número de empregados foram excluídas da amostra (tinham número de empregados maior do que 100.000, por provavelmente um erro na declaração). Com o objetivo de obter uma amostra mais homogênea quanto à idade e ao tempo de exposição à política, a amostra foi filtrada para captar apenas as empresas que aderiram ao Simples, a partir do ano de 2007, ano em que foi implementado o Simples Nacional. Após esses filtros, de um total de 449.098 observações para todo o período de análise, 56.028 (12\%) delas foram retiradas porque estavam associadas a empresas que foram beneficiadas em algum ano pelo Simples Federal. Após balancear a amostra, restaram 189.566 observações, das quais 179.130 (94\%) são de MPEs. A Tabela 1 apresenta estatísticas descritivas da amostra.

Tabela 1. Análise descritiva do número de empresas optantes e não optantes do Simples Nacional durante os 13 anos de análise

\begin{tabular}{|c|c|c|c|c|c|c|c|c|}
\hline & & & & & & Não & & \\
\hline & Todas & MPEs & Privadas & $\begin{array}{r}\text { Não } \\
\text { privadas }\end{array}$ & $\begin{array}{l}\text { Estran- } \\
\text { geira }\end{array}$ & $\begin{array}{l}\text { estran- } \\
\text { geira }\end{array}$ & RMR* & $\begin{array}{r}\text { Fora da } \\
\text { RMR }\end{array}$ \\
\hline Optantes & 6.224 & 6.174 & 6.207 & 17 & 0 & 6.224 & 3.681 & 2.543 \\
\hline Não optantes & 183.342 & 172.956 & 176.353 & 6.989 & 47 & 183.295 & 120.890 & 62.452 \\
\hline Total & 189.566 & 179.130 & 182.560 & 7.006 & 47 & 189.519 & 124.571 & 64.995 \\
\hline
\end{tabular}

Fonte: Elaboração própria. *RMR: Região Metropolitana de Recife.

A Figura 1 apresenta a evolução da média dos vínculos empregatícios, para a amostra de empresas consideradas na estimação dos modelos 1 e 2: grupo de tratamento, as MPEs beneficiadas pelo Simples Nacional; e grupo de controle, as MPEs não beneficiadas. A partir da Figura 1, percebe-se que, no período anterior à implementação da intervenção, os dois grupos de empresas apresentaram tendências paralelas de evolução do número médio de vínculos. Por outro lado, no período pós-política, esse indicador apresentou uma tendência de crescimento para o grupo de tratamento e permaneceu quase que estável para o grupo de controle. Os valores dessas médias, dos coeficientes de variação e dos desvios-padrão estão na Tabela A2 no apêndice.

De posse dessas evidências iniciais, verifica-se a seguir, se as diferenças entre as médias dos vínculos empregatícios do grupo de tratamento (MPEs beneficiadas pelo 
Simples Nacional) e do grupo de controle (MPEs que não estão no Simples Nacional) permanecem estatisticamente significantes nos resultados obtidos a partir da estimação dos modelos de regressão, mesmo após controlar pelas características individuais das firmas e locacionais.

Figura 1. Evolução das médias dos vínculos nas MPEs afetadas e não afetadas pelo Simples Nacional

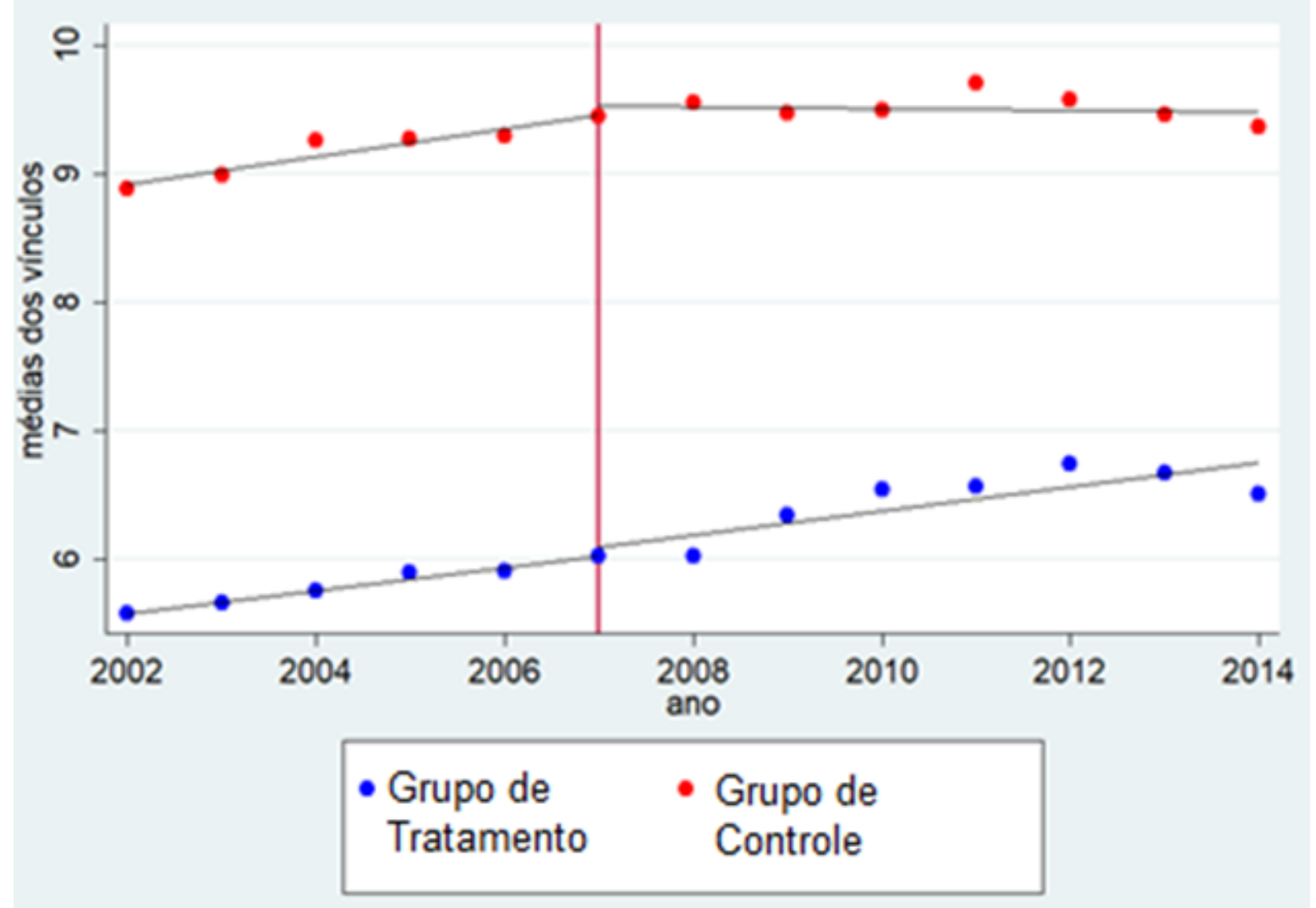

Fonte: Elaboração própria.

\section{Resultados e discussões}

Em todos os modelos, a variável dependente é o logaritmo natural do emprego. Cinco modelos foram estimados considerando o efeito fixo individual das firmas e das microrregiões. No modelo mais básico (modelo 1.1), apenas foi incorporada a variável dummy que indica se a MPE está no Simples Nacional. Para controlar pelas diferenças entre a atividade produtiva das empresas, no modelo 1.2 , foi adicionada uma variável dummy que identifica se a empresa é da indústria da transformação. O modelo 1.3 foi estimado com controles setoriais (variáveis dummies para cada divisão de atividades a 2-dígitos, segundo a CNAE 95; a divisão 80, educação, foi a categoria de comparação) ${ }^{14}$, e controles locacionais variantes no tempo (Densidade Demográfica, Emprego por Habitante e Salário Médio). No modelo 1.4, adicionou-se uma variável controle

\footnotetext{
${ }^{14}$ Ao rodar os modelos, omitiu-se a dummy referente à divisão 80 da CNAE 95 (Educação), pois ela mostrou maiores números de empregados dentre todas as divisões.
} 
para a natureza jurídica das empresas (empresas privadas, 0 caso contrário). Por fim, no modelo 1.5, considerou-se uma variável dummy que identifica se a empresa é estrangeira ( 0 caso contrário) ${ }^{15}$. A critério de comparação, todos os modelos também foram estimados considerando no grupo de tratamento, todas as empresas que foram beneficiadas pelo Simples (Federal ou Nacional) no período analisado. Os resultados encontram-se na Tabela A3, no apêndice, e são próximos aos obtidos para a amostra considerada na presente análise (ver Tabela 2).

Os testes de Breusch-Pagan e de Hausman foram aplicados para decidir o melhor modelo que deveria ser contemplado na análise (efeitos fixos, efeitos aleatórios ou o pooled), os quais apontaram para a escolha do modelo de efeitos fixos ${ }^{16}$. Em todos os modelos, foi aplicado o teste de raiz unitária Harris-Tzavalis e constatou-se que as séries são estacionárias. Os desvios-padrão são robustos à presença de heterocedasticidade. No geral, o principal coeficiente de interesse para a análise, que está associado ao indicador do Simples, mostrou-se estatisticamente significante a menos de 5\%, assim como o teste $F$ indicou para a significância conjunta das variáveis.

A Tabela 2 apresenta os resultados dos cinco modelos estimados com base na Equação (1) e, apenas a critério de comparação, adicionaram-se os resultados do modelo mais simples, estimado sem nenhum controle (primeira coluna da tabela). Ao comparar os resultados dos modelos estimados, observa-se que, em relação ao modelo estimado por $\mathrm{MQO}$, a maior mudança na magnitude do coeficiente associado ao Simples Nacional $\left(I N D S N_{i j t}\right)$ se dá quando se incorpora ao modelo o efeito fixo da firma. Esse resultado aponta que as características fixas no tempo das firmas são importantes como controle para esse tipo de modelo.

Porém, mesmo após controles individuais, observados e não observados, das firmas e locacional, os coeficientes estimados mantiveram-se quase na magnitude, indicando que as empresas que estão no Simples Nacional têm, em média, um nível mais elevado de emprego, quando comparadas ao grupo de controle. Mais precisamente, as empresas beneficiadas pelo Simples no estado de Pernambuco geraram, em média, 19,3\% mais emprego, quando comparadas ao grupo de controle. Mesmo os resultados não sendo comparáveis diretamente aos demais estudos empíricos citados na presente pesquisa, já que há diferenças, tanto no recorte setorial quanto no geográfico, a estimativa aqui obtida foi bem próxima da obtida por Franco et al. (2017).

Esses resultados apontam para um efeito positivo direto da política na criação de novos postos de trabalho no estado, o que deve fortalecer a importância das MPEs para a economia local. Além disso, um efeito indireto que deve emergir dessa política está relacionado aos efeitos aglomerativos que esse tipo de empresa tem sobre setores especializados e concentrados espacialmente (Rosenthal e Strange, 2010), gerando um efeito multiplicador para toda a economia. Assim, dada a estrutura produtiva do

\footnotetext{
${ }^{15}$ Mais detalhes sobre quais empresas estão em cada um dos dois grupos pode ser encontrados na Tabela Al no apêndice.

${ }^{16}$ Apenas para o modelo 3.5, não se pode escolher o modelo de efeito fixo em relação ao aleatório.
} 
estado de Pernambuco, políticas fiscais que beneficiam os micros e pequenos empresários devem ser relativamente mais importantes para o estado, quando comparado a outros estados que têm uma economia mais desenvolvida, como São Paulo, que concentra quase $30 \%$ das grandes empresas do país.

Tabela 2. Resultados dos modelos estimados a partir da Equação (1) por MQO e com efeitos fixos para as MPEs.

Variável dependente: logaritmo do emprego $(\log -\operatorname{lin})$

\begin{tabular}{|c|c|c|c|c|c|c|}
\hline $\begin{array}{l}\text { Variáveis } \\
\text { explicativas }\end{array}$ & MQO & $\begin{array}{l}\text { Modelo } 1.1 \\
\text { Efeito Fixo }\end{array}$ & $\begin{array}{l}\text { Modelo } 1.2 \\
\text { Efeito Fixo }\end{array}$ & $\begin{array}{l}\text { Modelo } 1.3 \\
\text { Efeito Fixo }\end{array}$ & $\begin{array}{l}\text { Modelo } 1.4 \\
\text { Efeito Fixo }\end{array}$ & $\begin{array}{l}\text { Modelo } 1.5 \\
\text { Efeito Fixo }\end{array}$ \\
\hline \multirow{2}{*}{ INDSN } & $-0,1115^{* *}$ & $0,1781^{* *}$ & $0,1779^{* *}$ & $0,1763^{* *}$ & $0,1764^{* *}$ & $0,1764 * *$ \\
\hline & $(0,0153)$ & $(0,0072)$ & $(0,0072)$ & $(0,0072)$ & $(0,0072)$ & $(0,0072)$ \\
\hline IndTrans & & & $\begin{array}{l}0,0946^{* *} \\
(0,0178)\end{array}$ & & & \\
\hline \multirow{2}{*}{ Privada } & & & & & $-0,0284$ & $-0,0284$ \\
\hline & & & & & $(0,0202)$ & $(0,0202)$ \\
\hline \multirow{2}{*}{ Estrangeira } & & & & & & 0,8777 \\
\hline & & & & & & $(0,1228)$ \\
\hline Densidade & & & & $-9,10 \mathrm{e}-06^{* *}$ & $-9,11 \mathrm{e}-06^{* *}$ & $-9,11 \mathrm{e}-06^{* *}$ \\
\hline Demográfica & & & & $(3,21 \mathrm{e}-06)$ & $(3,21 \mathrm{e}-06)$ & $(3,21 \mathrm{e}-06)$ \\
\hline Emprego por & & & & $-0,0588^{*}$ & $-0,0581^{*}$ & $0,0586^{*}$ \\
\hline Habitante & & & & $(0,0334)$ & $(0,0334)$ & $(0,0334)$ \\
\hline Salário & & & & $3,57 \mathrm{e}-08^{* *}$ & $3,56 \mathrm{e}-08^{* *}$ & $3,56 \mathrm{e}-08^{* *}$ \\
\hline Médio & & & & $(7,57 \mathrm{e}-09)$ & $(7,57 \mathrm{e}-09)$ & $(7,57 \mathrm{e}-09)$ \\
\hline Divisão & & & & Sim & Sim & Sim \\
\hline $\begin{array}{l}\text { Efeito Fixo } \\
\text { Tempo }\end{array}$ & Sim & Sim & Sim & Sim & Sim & Sim \\
\hline $\begin{array}{l}\text { Efeito Fixo } \\
\text { Microrregião }\end{array}$ & Sim & Sim & Sim & Sim & Sim & Sim \\
\hline \multirow{2}{*}{ Constante } & $2,0511^{* *}$ & $1,4466^{* *}$ & $1,4436^{* *}$ & $1,5646^{* *}$ & $1,5917^{* *}$ & $1,5916^{* *}$ \\
\hline & $(0,104)$ & $(0,2727)$ & $(0,2727)$ & $(0,2736)$ & $(0,2742)$ & $(0,2743)$ \\
\hline Teste F & $211,33^{* *}$ & $37,96 * *$ & $37,67^{* *}$ & $19,05^{* *}$ & $18,86^{* *}$ & $18,67^{* *}$ \\
\hline Observações & 179.130 & 179.130 & 179.130 & 179.130 & 179.130 & 179.130 \\
\hline
\end{tabular}

Fonte: Elaboração própria. Nota: desvios-padrão entre parênteses.

**Significativo a $1 \%$. *Significativo a $5 \%$. 
Em relação às variáveis controles, há indicações para uma associação negativa do nível de emprego das MPEs com a densidade demográfica; e positiva com a densidade do emprego e com o salário médio. Esses resultados sugerem que, em média, as MPEs de cidades que geram mais emprego e pagam maiores salários também apresentam um maior nível de emprego, quando comparadas com os seus pares.

Os resultados estimados com base na Equação 2, encontram-se na Tabela 3.

Nos modelos da Tabela 3, foram consideradas variáveis dummies do tempo de adesão ao Simples Nacional, como indicadores de avaliação da intervenção, mantendo-se todas as demais variáveis dos modelos da Tabela 2. A partir dessas estimações, é possível perceber que há uma tendência média de aumento do número de vínculos empregatícios das empresas que estão no Simples, pelo menos até o sexto ano da intervenção. Esses resultados corroboram uma avaliação positiva da política para a geração de emprego formal no estado e, possivelmente, em todo o país. Pelo fato de o sistema simplificado de tributação gerar uma economia financeira para as MPEs, há um aumento da margem de lucro dessas empresas, as quais podem reinvestir, expandindo a produção e, consequentemente, ampliando os investimentos em capital físico e humano. Por outro lado, destacam-se, também, as vantagens da política ao incentivar a formalização das micro e pequenas empresas, conforme já evidenciado por Kalume et al. (2012); Paes (2015), fato não explorado aqui por não ser objeto de análise deste estudo.

Com o objetivo de dar mais robustez aos resultados, com base na Equação 3, também foi estimado um modelo considerando como grupo de tratamento apenas as empresas que aderiram ao Simples Nacional durante os oito anos consecutivos, totalizando 155.490 observações de 12.908 MPEs.

Os resultados dispostos na Tabela 4 corroboram os obtidos anteriormente e, como esperado, os coeficientes associados à variável que capta o impacto da política são mais elevados: apontam que as empresas que permaneceram oito anos no Simples geraram, em média, 29\% a mais de emprego, quando comparadas com as empresas não beneficiadas pelo regime tributário. Esse coeficiente é em torno de $67 \%$ maior do que o impacto médio obtido pelos modelos anteriores (o coeficiente estimado associado a política foi de 19,3\%).

Buscando dar mais robustez aos resultados, a seguir, apresentam-se os resultados dos modelos estimados com a incorporação de variáveis dummies de leads e Lags. 
Tabela 3. Resultados dos modelos estimados a partir da equação por MQO e com efeitos fixos para as MPEs

Variável dependente: logaritmo do emprego $(\log -\operatorname{lin})$ com dummies de tempo no Simples

\begin{tabular}{|c|c|c|c|c|c|c|}
\hline & MQO & Modelo 2.1 & Modelo 2.2 & Modelo 2.3 & Modelo 2.4 & Modelo 2.5 \\
\hline \multicolumn{7}{|c|}{ Dummies de tempo que a empresa está no Simples } \\
\hline \multirow[t]{2}{*}{1 ano } & $-0,2912^{* *}$ & $0,0527^{* *}$ & $0,0525^{* *}$ & $0,0522 * *$ & $0,0522 * *$ & $0,0522^{* *}$ \\
\hline & $(0,0246)$ & $(0,0098)$ & $(0,0098)$ & $(0,0098)$ & $(0,0098)$ & $(0,0098)$ \\
\hline \multirow[t]{2}{*}{2 anos } & $-0,1296 * *$ & $0,1779 * *$ & $0,1778^{* *}$ & $0,1768^{* *}$ & $0,1769 * *$ & $0,1769 * *$ \\
\hline & $(0,0342)$ & $(0,0137)$ & $(0,0137)$ & $(0,0137)$ & $(0,0137)$ & $(0,0137)$ \\
\hline \multirow[t]{2}{*}{3 anos } & $-0,0416$ & $0,2568^{* *}$ & $0,2569 * *$ & $0,2543^{* *}$ & $0,2544^{* *}$ & $0,2544^{* *}$ \\
\hline & $(0,0401)$ & $(0,016)$ & $(0,016)$ & $(0,016)$ & $(0,016)$ & $(0,016)$ \\
\hline \multirow[t]{2}{*}{4 anos } & 0,0472 & $0,3414^{* *}$ & $0,3413^{* *}$ & $0,3393^{* *}$ & $0,3393^{* *}$ & $0,3393^{* *}$ \\
\hline & $(0,0463)$ & $(0,0185)$ & $(0,0185)$ & $(0,0185)$ & $(0,0185)$ & $(0,0185)$ \\
\hline \multirow[t]{2}{*}{5 anos } & $0,122^{*}$ & $0,4052^{* *}$ & $0,4047^{* *}$ & $0,4014^{* *}$ & $0,4014^{* *}$ & $0,4014^{* *}$ \\
\hline & $(0,0533)$ & $(0,0213)$ & $(0,0213)$ & $(0,0213)$ & $(0,0213)$ & $(0,0213)$ \\
\hline \multirow[t]{2}{*}{6 anos } & $0,1804^{* *}$ & $0,4433^{* *}$ & $0,4427^{* *}$ & $0,4388^{* *}$ & $0,4388^{* *}$ & $0,4388^{* *}$ \\
\hline & $(0,0618)$ & $(0,0247)$ & $(0,0247)$ & $(0,0247)$ & $(0,0247)$ & $(0,0247)$ \\
\hline \multirow[t]{2}{*}{7 anos } & 0,0803 & $0,4064 * *$ & $0,4059 * *$ & $0,4042^{* *}$ & $0,4041^{* *}$ & $0,4041^{* *}$ \\
\hline & $(0,0763)$ & $(0,0304)$ & $(0,0304)$ & $(0,0304)$ & $(0,0304)$ & $(0,0304)$ \\
\hline \multirow[t]{2}{*}{8 anos } & 0,0059 & $0,3678^{* *}$ & $0,3669^{* *}$ & $0,3623^{* *}$ & $0,3623^{* *}$ & $0,3623^{* *}$ \\
\hline & $(0,104)$ & $(0,0413)$ & $(0,0413)$ & $(0,0412)$ & $(0,0412)$ & $(0,0412)$ \\
\hline \multirow{2}{*}{ IndTrans } & & & $0,0933^{* *}$ & & & \\
\hline & & & $(0,0177)$ & & & \\
\hline \multirow{2}{*}{ Privada } & & & & & $-0,02712$ & $-0,02712$ \\
\hline & & & & & $(0,0202)$ & $(0,0202)$ \\
\hline \multirow{2}{*}{ Estrangeira } & & & & & & 0,0798 \\
\hline & & & & & & $(0,1226)$ \\
\hline Densidade & & & & $-9,01 \mathrm{e}-06^{* *}$ & $-9,01 \mathrm{e}-06^{* *}$ & $-9,01 \mathrm{e}-06^{* *}$ \\
\hline Demográfica & & & & $(3,20 \mathrm{e}-06)$ & $(3,20 \mathrm{e}-06)$ & $(3,20 \mathrm{e}-06)$ \\
\hline Emprego por & & & & $-0,0516$ & $-0,0515$ & $-0,0515$ \\
\hline Habitante & & & & $(0,3333)$ & $(0,3333)$ & $(0,3333)$ \\
\hline \multirow{2}{*}{ Salário Médio } & & & & $3,40 \mathrm{e}-08^{* *}$ & $3,39 \mathrm{e}-08^{* *}$ & $3,39 \mathrm{e}-08^{* *}$ \\
\hline & & & & $(7,56 \mathrm{e}-09)$ & $(7,56 \mathrm{e}-09)$ & $(7,56 \mathrm{e}-09)$ \\
\hline Divisão & & & & Sim & Sim & Sim \\
\hline $\begin{array}{l}\text { Efeito Fixo } \\
\text { Tempo }\end{array}$ & Sim & Sim & Sim & Sim & Sim & Sim \\
\hline $\begin{array}{l}\text { Efeito Fixo } \\
\text { Microrregião }\end{array}$ & Sim & Sim & Sim & Sim & Sim & Sim \\
\hline \multirow{2}{*}{ Constante } & $2,0413^{* *}$ & $1,4359 * *$ & $1,4329^{* *}$ & $1,5466^{* *}$ & $1,5725^{* *}$ & $1,5723^{* *}$ \\
\hline & $(0,104)$ & $(0,2723)$ & $(0,2723)$ & $(0,2732)$ & $(0,2738)$ & $(0,2738)$ \\
\hline Teste $\mathrm{F}$ & $175,61^{* *}$ & $44,77^{* *}$ & $44,34^{* *}$ & $22,93^{* *}$ & $22,72^{* *}$ & $22,5^{* *}$ \\
\hline Observações & 179.130 & 179.130 & 179.130 & 179.130 & 179.130 & 179.130 \\
\hline
\end{tabular}

Fonte: Elaboração própria. Nota: desvios-padrão entre parênteses.

**Significativo a $1 \%$. *Significativo a $5 \%$. 
Tabela 4. Resultados dos modelos estimados a partir da Equação (1) por MQO e com efeitos fixos para as MPEs. Variável Dependente: Logaritmo do Emprego $(\log -\operatorname{lin})$

Amostra: empresas que optaram pelo Simples durante os oito anos consecutivos

\begin{tabular}{|c|c|c|c|c|c|c|}
\hline & MQO & Modelo 3.1 & Modelo 3.2 & Modelo 3.3 & Modelo 3.4 & Modelo 3.5 \\
\hline \multirow{2}{*}{$I N D S N T_{i j}$} & 0,1466 & $0,2547^{* *}$ & $0,2534^{* *}$ & $0,2553^{* *}$ & $0,2553^{* *}$ & $0,2554 * *$ \\
\hline & $(0,0609)$ & $(0,0358)$ & $(0,0358)$ & $(0,0358)$ & $(0,0358)$ & $(0,0358)$ \\
\hline \multirow{2}{*}{ IndTrans } & & & $0,0916^{* *}$ & & & \\
\hline & & & $(0,0201)$ & & & \\
\hline \multirow{2}{*}{ Privada } & & & & & $-0,0345$ & $-0,0345$ \\
\hline & & & & & $(0,0208)$ & $(0,0208)$ \\
\hline \multirow{2}{*}{ Estrangeira } & & & & & & $-0,2156$ \\
\hline & & & & & & $(0,1378)$ \\
\hline Densidade & & & & $-0,00001^{* *}$ & $-0,00001^{* *}$ & $-0,00001^{* *}$ \\
\hline Demográfica & & & & $(3,41 \mathrm{e}-06)$ & $(3,41 \mathrm{e}-06)$ & $(3,41 \mathrm{e}-06)$ \\
\hline Emprego por & & & & $-0,072^{*}$ & $-0,0716^{*}$ & $-0,0716^{*}$ \\
\hline Habitante & & & & $(0,035)$ & $(0,035)$ & $(0,035)$ \\
\hline \multirow{2}{*}{ Salário Médio } & & & & $2,22 \mathrm{e}-08^{* *}$ & $2,21 \mathrm{e}-08^{* *}$ & $2,22 \mathrm{e}-08^{* *}$ \\
\hline & & & & $(7,99 e-09)$ & $(7,99 \mathrm{e}-09)$ & $(7,99 \mathrm{e}-09)$ \\
\hline Divisão & & & & Sim & Sim & Sim \\
\hline $\begin{array}{l}\text { Efeito Fixo } \\
\text { Tempo }\end{array}$ & Sim & Sim & Sim & Sim & Sim & Sim \\
\hline $\begin{array}{l}\text { Efeito Fixo } \\
\text { Microrregião }\end{array}$ & Sim & Sim & Sim & Sim & Sim & Sim \\
\hline \multirow{2}{*}{ Constante } & $1,1397^{* *}$ & $1,4835^{* *}$ & $1,4809^{* *}$ & $1,505^{* *}$ & $1,5375^{* *}$ & $1,5378^{* *}$ \\
\hline & $(0,0371)$ & $(0,2655)$ & $(0,2654)$ & $(0,2665)$ & $(0,2672)$ & $(0,2672)$ \\
\hline Teste F & $207,16^{* *}$ & $21,32^{* *}$ & $21,31^{* *}$ & $13,49^{* *}$ & $13,38^{* *}$ & $13,26 * *$ \\
\hline Observações & 155.490 & 155.490 & 155.490 & 155.490 & 155.490 & 155.490 \\
\hline
\end{tabular}

Fonte: Elaboração própria. Nota: desvios-padrão entre parênteses.

**Significativo a $1 \%$. *Significativo a $5 \%$. 


\section{Leads \& lags}

Baseando-se em Angrist e Pischke (2008), foi estimado um modelo com leads e lags, com o objetivo de verificar se há diferenças estatisticamente significantes entre as médias do nível de emprego, do grupo de tratamento e controle, no período pré-tratamento, em especial, e pós-tratamento. Os resultados desses modelos são mais uma fonte de informação para dar robustez aos resultados já obtidos. A ideia desses modelos é verificar se as empresas que aderiram aos Simples Nacional são pré-selecionadas, se as empresas pertencentes ao grupo de tratamento já apresentavam alguma tendência de aumento do emprego antes da opção pelo Simples, de modo que isso poderia superestimar a estimativa do impacto da intervenção na variável de resultado. Já as variáveis dummys de lags devem captar mudanças do efeito de tratamento ao longo do tempo (Oliveira, 2016), se há uma tendência de crescimento, por exemplo. Para tal estimação, tem-se com base a especificação econométrica sugerida por Angrist e Pischke (2008):

$$
\ln \left(V_{i j}\right)=\delta_{0}+\sum_{\tau=0}^{m} \delta_{-\tau} D_{i, t-\tau}+\sum_{\tau=1}^{q} \delta_{+\tau} D_{i, t+\tau}+X_{i j t} \delta_{2}+Z_{j t} \delta_{3}+\eta_{i}+z_{j}+\gamma_{t}+\varepsilon_{i j t}
$$

em que as variáveis $D_{i, t-\tau}$ são $m$ dummies de lags (efeitos pós-tratamento) e $D_{i, t+\tau}$ são $q$ dummies de leads (efeitos antecipatórios) que variam de $t-\tau$ e $t+\tau$. A dummy $D_{i, t-\tau}$ assume valor igual a 1 se a observação se refere à empresa i em um momento " $t-\tau$ " (ou $m$ ) anos antes de ela aderir ao programa. A dummy $D_{i, t+\tau}$ vale 1 se a observação se refere à empresa i em um momento " $t+\tau$ " (ou $q$ ) anos após ela aderir ao programa. As empresas não beneficiadas pelo Simples receberam valor zero nas variáveis dummies. As demais variáveis controles são as mesmas dos modelos anteriores. Desse modo, foram considerados três anos para as dummies de leads e três para os lags.

A Tabela 5 apresenta os resultados dos modelos estimados, a partir da mesma amostra considerada para a estimação dos modelos 1 (179.130 observações de 14.115 MPEs). De posse desses resultados, observa-se que há um efeito positivo estatisticamente significante a 5\% para as dummies leads, porém com um coeficiente de magnitude em torno de $2 \%$ (ano mais antigo) e 5\% (ano mais recente). Trata-se de um efeito positivo pós-política, como o esperado. O ideal seria que as variáveis dummies leads apresentassem coeficientes não significantes, indicando que o grupo de tratamento não apresentava uma tendência de crescimento do emprego, quando comparado com o grupo de controle. Porém, mesmo diante desses resultados obtidos, estima-se que o coeficiente de impacto da política, previamente obtido, é válido e deve ser em torno de $14 \%$ a $19 \%$. Os resultados obtidos para os modelos 3 (amostra de MPEs que permaneceram no Simples Nacional durante os oito anos consecutivos), encontram-se na Tabela A4 (no apêndice) e as dummies leads e lags não se mostraram estatisticamente significantes e menores de 5\%. 
Tabela 5. Impacto do Simples em Pernambuco - Modelo com leads e lags Amostra: empresas que optaram pelo Simples durante os oito anos consecutivos

\begin{tabular}{|c|c|c|c|c|c|c|}
\hline & OLS & Modelo 1 & Modelo 2 & Modelo 3 & Modelo 4 & Modelo 5 \\
\hline \multicolumn{7}{|c|}{ Leads (distância pré-política) } \\
\hline \multirow{2}{*}{-3 anos } & $-0,18^{* *}$ & $0,0185^{*}$ & $0,0187^{*}$ & $0,0187^{*}$ & $0,0187^{*}$ & $0,0187^{*}$ \\
\hline & $(0,0196)$ & $(0,0081)$ & $(0,0081)$ & $(0,0081)$ & $(0,0081)$ & $(0,0081)$ \\
\hline \multirow[t]{2}{*}{-2 anos } & $-0,0637^{* *}$ & $0,031^{* *}$ & $0,0309^{* *}$ & $0,0306^{* *}$ & $0,0306^{* *}$ & $0,0306^{* *}$ \\
\hline & $(0,0221)$ & $(0,0085)$ & $(0,0085)$ & $(0,0085)$ & $(0,0085)$ & $(0,0085)$ \\
\hline \multirow[t]{2}{*}{-1 ano } & $-0,0402$ & $0,053^{* *}$ & $0,0529^{* *}$ & $0,0517^{* *}$ & $0,0517^{* *}$ & $0,0517^{* *}$ \\
\hline & $(0,0212)$ & $(0,0081)$ & $(0,0081)$ & $(0,0081)$ & $(0,0081)$ & $(0,0081)$ \\
\hline \multicolumn{7}{|c|}{ Lags (distância pós-política) } \\
\hline \multirow[t]{2}{*}{+1 ano } & 0,0264 & $0,1142^{* *}$ & $0,1142^{* *}$ & $0,1139 * *$ & $0,114^{* *}$ & $0,114^{* *}$ \\
\hline & $(0,0243)$ & $(0,0093)$ & $(0,0093)$ & $(0,0093)$ & $(0,0093)$ & $(0,0093)$ \\
\hline \multirow[t]{2}{*}{+2 anos } & $-0,0079$ & $0,0763^{* *}$ & $0,0761^{* *}$ & $0,0743^{* *}$ & $0,0744^{* *}$ & $0,0744^{* *}$ \\
\hline & $(0,0277)$ & $(0,0106)$ & $(0,0106)$ & $(0,0106)$ & $(0,0106)$ & $(0,0106)$ \\
\hline \multirow[t]{2}{*}{+3 anos } & $-0,025$ & $0,0916^{* *}$ & $0,0916^{* *}$ & $0,0902^{* *}$ & $0,0902^{* *}$ & $0,0901^{* *}$ \\
\hline & $(0,0277)$ & $(0,0108)$ & $(0,0108)$ & $(0,0108)$ & $(0,0108)$ & $(0,0108)$ \\
\hline \multirow{2}{*}{ IndTrans } & & & $0,0939^{* *}$ & & & \\
\hline & & & $(0,0177)$ & & & \\
\hline \multirow{2}{*}{ Privada } & & & & & $-0,0281$ & $-0,0281$ \\
\hline & & & & & $(0,0202)$ & $(0,0202)$ \\
\hline \multirow{2}{*}{ Estrangeira } & & & & & & 0,0849 \\
\hline & & & & & & $(0,1227)$ \\
\hline Densidade & & & & $-8,88 \mathrm{e}-06^{* *}$ & $-8,88 \mathrm{e}-06^{* *}$ & $-8,88 \mathrm{e}-06^{* *}$ \\
\hline Demográfica & & & & $(3,20 \mathrm{e}-06)$ & $(3,20 \mathrm{e}-06)$ & $(3,20 \mathrm{e}-06)$ \\
\hline Emprego por & & & & $-0,0519$ & $-0,0517$ & $-0,0517$ \\
\hline Habitante & & & & $(0,0333)$ & $(0,0333)$ & $(0,0333)$ \\
\hline \multirow{2}{*}{ Salário Médio } & & & & $3,37 e-08^{* *}$ & $3,37 \mathrm{e}-08^{* *}$ & $3,37 \mathrm{e}-08^{* *}$ \\
\hline & & & & $(7,56 e-09)$ & $(7,56 e-09)$ & $(7,56 e-09)$ \\
\hline Divisão & & & & Sim & Sim & Sim \\
\hline $\begin{array}{l}\text { Dummies de Ano } \\
\text { e Microrregião }\end{array}$ & Sim & Sim & Sim & Sim & Sim & Sim \\
\hline \multirow{2}{*}{ Constante } & $2,0601^{* *}$ & $1,4371^{* *}$ & $1,4341^{* *}$ & $1,5489^{* *}$ & $1,5757^{* *}$ & $1,5755^{* *}$ \\
\hline & $(0,104)$ & $(0,2725)$ & $(0,2725)$ & $(0,2733)$ & $(0,274)$ & $(0,274)$ \\
\hline Teste F & $187,87^{* *}$ & $40,88^{* *}$ & $40,54^{* *}$ & $20,97^{* *}$ & $20,77^{* *}$ & $20,57^{* *}$ \\
\hline Observações & 179.130 & 179.130 & 179.130 & 179.130 & 179.130 & 179.130 \\
\hline
\end{tabular}

Fonte: Elaboração própria. Nota: desvios-padrão entre parênteses.

**Significativo a $1 \%$. *Significativo a $5 \%$. 


\section{Conclusão}

O presente artigo apresenta evidências da contribuição do Simples Nacional para a geração de emprego pelas MPEs beneficiadas pelo regime diferenciado de tributação e que estão instaladas no estado de Pernambuco. Os microdados identificados da RAIS foram utilizados de modo que foi possível a construção de um painel de dados, ao nível das firmas, para o período compreendido entre 2002 e 2014. Para tanto, o ano de 2007, a partir do qual passou a vigorar o Simples Nacional, foi considerado como ano de referência da intervenção da política. Deste modo, definiram-se como grupo de tratamento as MPEs beneficiadas pelo regime tributário instituído pelo Simples Nacional (no ano de 2006) e como grupo de controle as MPEs não contempladas. A análise baseou-se em estimações de modelos de regressão com a incorporação de controles para as características não observáveis e fixas no tempo das firmas e microrregiões, e demais controles das firmas e locacionais variantes no tempo.

Do conjunto de resultados, pode-se concluir que há um diferencial positivo no emprego gerado pelas MPEs beneficiadas pelo Simples Nacional (em média 19\%), em comparação às empresas que não estão, resultado esse que se mantem válido mesmo após a incorporação dos controles das firmas e locacionais. Além disso, os resultados sugerem que esse diferencial cresce na medida em que a empresa se mantém no Simples, sendo máximo no sexto ano no programa, indicando um efeito positivo do Simples na geração de emprego. Esses resultados reforçam os prévios estudos aqui citados, que, apesar de explorarem outros objetos de análise, também concluíram que há um efeito positivo da adoção de um sistema simplificado e com alíquotas diferenciadas para as MPEs na geração de emprego e renda.

A pesquisa apresenta relevantes contribuições à literatura, apesar das suas limitações, especialmente devido à falta de informação sobre a receita das empresas. Primeiramente, ao expandir a análise para todo o setor produtivo da economia, o estudo agrega evidências à previa literatura existente, das externalidades positivas geradas pelo Simples Nacional, para além do setor industrial. A pesquisa também apresenta resultados inéditos para Pernambuco, estado que tem sua economia fortemente dependente das MPEs, as quais integram importantes polos produtivos especializados, com destaque para o polo têxtil/confecção, o polo de informática e o de saúde, todos com uma importância nacional.

Como sugestão para trabalhos futuros, pretende-se fazer uma análise do efeito multiplicador do emprego gerado pelas MPEs do setor industrial que estão no Simples sobre os demais setores da economia, como também expandir esta pesquisa para uma análise de custo-efetividade da política. Ademais, destaca-se a importância de estudos de avaliação como este, especialmente para o Simples Nacional, que representa o principal gasto tributário do país (segundo a PLOA de 2020, responderá por 25\% do total dos gastos tributários do país). 


\section{Referências}

Aghion, P., Akcigit, U., Lequien, M., e Stantcheva, S. (2017). Do entrepreneurship and selfemployment respond to simpler fiscal incentives? Evidence from France. Texto para discussão, Working Paper.

Andrade, B. A., Rocha, R. M., e Moura, K. H. L. (2016). Distribuição espacial da indústria têxtil e de confecção em Pernambuco: qual a influência dos fatores locacionais? Economia e Desenvolvimento, 15:93-112.

Angrist, J. D. e Pischke, J.-S. (2008). Mostly harmless econometrics: An empiricist's companion. Princeton university press.

Araújo, A. d. L. L. (2008). O impacto do SIMPLES no mercado de trabalho do setor industrial no nordeste do Brasil. Dissertação (Mestrado) - Universidade Federal do Ceará, Curso de Pós-Graduação em Economia. Mestrado Profissional em Economia.

Bank, W. (2013). Doing Business 2013: smarter regulations for small and medium-size enterprises. The World Bank.

Bartik, T. J. (1991). Who benefits from state and local economic development policies? WE Upjohn Institute for Employment Research.

Brasil (1996). Lei no 9.317. Disponivel em: https://www.planalto. gov.br>.

Brasil (2016). Lei Complementar no 123. Disponível em: http://www. planalto.gov.br.

Chaurey, R. (2017). Location-based tax incentives: evidence from India. Journal of Public Economics, 156:101-120.

Conceição, O. C., Fochezatto, A., França, M. T. A., e Saraiva, M. V. (2016). O Simples Nacional e as empresas industriais: uma análise de sobrevivência a partir de microdados da RAIS. Prêmio CNI de Economia 2016.

Corseuil, C. H. L. e Moura, R. L. (2011). O impacto do simples federal no nível de emprego da indústria brasileira. Texto para Discussão 1643, Instituto de Pesquisa Econômica Aplicada (IPEA).

Ellison, G. e Glaeser, E. L. (1997). Geographic concentration in US manufacturing industries: a dartboard approach. Journal of Political Economy, 105(5):889-927.

Fernandes, A. C. e Lima, J. P. R. (2006). Cluster de serviços: contribuições conceituais com base em evidências do pólo médico do recife. Nova Economia, 16(1):11-47.

Franco, C., Sampaio, G. R., e Vaz, P. H. (2017). Redução e Simplificação de Tributos para Empresas de Pequena Porte: uma Aplicação de Regressão Descontinua para a Indústria Brasileira. Encontro de Economia da Região Sul.

Giroud, X. e Rauh, J. (2019). State taxation and the reallocation of business activity: Evidence from establishment-level data. Journal of Political Economy, 127(3):12621316. 
Kalume, L., Corseuil, C. H. L., e Santos, D. D. (2012). Simples nacional e formalização das firmas no Rio de Janeiro. Encontro Nacional de Economia.

Leal Brito, R. N. e Alcantara, S. A. (2012). As microempresas e seu regime tributário diferenciado. Revista Organização Sistêmica, 2(1):140-153.

Lima Neto, C. C. (2009). O Impacto do Simples na Geração de Emprego para o Setor Têxtil nas Microrregiões brasileiras no Periodo de 1995-2005. Dissertação (Mestrado) - Universidade Federal do Ceará, Curso de Pós-Graduação em Economia.

Lyra, F. T., Pinheiro, V., e Sarmento, V. (1995). Os incentivos fiscais à indústria da Zona Franca de Manaus: uma avaliação (relatório final). Instituto de Pesquisa Econômica Aplicada (Ipea).

Oliveira, A. M. D. (2016). Impacto econômico de investimentos em infraestrutura de transporte rodoviário: avaliação do Programa Estradeiro nos municípios do estado de Mato Grosso. Tese (Doutorado). Universidade Federal de Pernambuco.

Paes, N. L. (2015). Reflexos do simples nacional no emprego e na formalização do mercado de trabalho no Brasil. Economía, sociedad y territorio, 15(49):639-663.

Puga, F. P. (2000). Experiências de apoio às micro, pequenas e médias empresas nos Estados Unidos, na Itália e em Taiwan. Banco Nacional de Desenvolvimento Econômico e Social.

RAIS (2014). Relação Anual de Informações Sociais. Ministério da Economia.

Rocha, R., da Silva Júnior, L. H., e Viana, J. A. B. (2015). Inovação e competição: um estudo de caso do arranjo produtivo de confecção do agreste pernambucano. Gestão e Desenvolvimento em Revista, 1(1):50-80.

Rocha, R., Magalhaes, A. M., e Junior, J. L. T. (2009). Aglomerações geográficas e sistemas produtivos locais: uma análise para o arranjo produtivo de informática de Recife. Revista Brasileira de Estudos Regionais e Urbanos, 3(2):47-68.

Rosenthal, S. S. e Strange, W. C. (2010). Small establishments/big effects: Agglomeration, industrial organization and entrepreneurship. In: Agglomeration Economics, Página 277-302. University of Chicago Press.

SEBRAE (2012). Estudo Econômico do Arranjo Produtivo Local de Confecções do Agreste Pernambucano. Serviço Brasileiro de Apoio às Micro e Pequenas Empresas.

SEBRAE (2013). Pequenos negócios no Brasil. Serviço Brasileiro de Apoio às Micro e Pequenas Empresas.

Souza Filho, F. (2009). Clusters e distritos industriais: estudos de casos em países selecionados e implicações de política. Planejamento e Politicas Públicas, 21:50-78. 
Thomsen, M., Ullmann, R., Watrin, C., e Dyreng, S. D. (2013). The impact of taxes on location decisions. School of Business Administration and Economics, Institute of Accounting and Taxation, University of Muenster, Muenster, Germany.

(@) Ev Este artigo está licenciado com uma CC BY 4.0 license. 


\section{Anexo}

Tabela A1. Natureza Jurídica das Empresas

\begin{tabular}{|c|c|c|}
\hline & Privada & $\begin{array}{l}\text { Estrangeira } \\
\text { (com fins } \\
\text { lucrativos) }\end{array}$ \\
\hline Órgão Público do Poder Executivo Federal & Não & Não \\
\hline Órgão Público do Poder Executivo Estadual ou do Distrito Federal & Não & Não \\
\hline Órgão Público do Poder Executivo Municipal & Não & Não \\
\hline Órgão Público do Poder Legislativo Federal & Não & Não \\
\hline Órgão Público do Poder Legislativo Estadual ou do Distrito Federal & Não & Não \\
\hline Órgão Público do Poder Legislativo Municipal & Não & Não \\
\hline Órgão Público do Poder Judiciário Federal & Não & Não \\
\hline Órgão Público do Poder Judiciário Estadual & Não & Não \\
\hline Autarquia Federal & Não & Não \\
\hline Autarquia Estadual ou do Distrito Federal & Não & Não \\
\hline Autarquia Municipal & Não & Não \\
\hline Fundação Federal & Não & Não \\
\hline Fundação Estadual ou do Distrito Federal & Não & Não \\
\hline Fundação Municipal & Não & Não \\
\hline Órgão Público Autônomo Federal & Não & Não \\
\hline Órgão Público Autônomo Estadual ou do Distrito Federal & Não & Não \\
\hline Órgão Público Autônomo Municipal & Não & Não \\
\hline Comissão Polinacional & Não & Não \\
\hline Fundo Público & Não & Não \\
\hline Associação Pública & Não & Não \\
\hline Empresa Pública & Não & Não \\
\hline Sociedade de Economia Mista & Sim & Não \\
\hline Sociedade Anônima Aberta & Sim & Não \\
\hline Sociedade Anônima Fechada & Sim & Não \\
\hline Sociedade Empresária Limitada & Sim & Não \\
\hline Sociedade Empresária em Nome Coletivo & Sim & Não \\
\hline Sociedade Empresária em Comandita Simples & Sim & Não \\
\hline Sociedade Empresária em Comandita por Ações & Sim & Não \\
\hline Sociedade Mercantil de Capital e Indústria & Sim & Não \\
\hline Sociedade Civil & Sim & Não \\
\hline Sociedade em Conta de Participação & Sim & Não \\
\hline Empresário (Individual) & Sim & Não \\
\hline Cooperativa & Sim & Não \\
\hline
\end{tabular}


Tabela A1. Natureza Jurídica das Empresas (continuação)

\begin{tabular}{|c|c|c|}
\hline & Privada & $\begin{array}{l}\text { Estrangeira } \\
\text { (com fins } \\
\text { lucrativos) }\end{array}$ \\
\hline Consórcio de Sociedades & Sim & Não \\
\hline Grupo de Sociedades & Sim & Não \\
\hline Estabelecimentos, no Brasil, de Sociedade Estrangeira & Sim & Sim \\
\hline Estabelecimento, no Brasil, de Empresa Binacional Argentino-Brasileira & Sim & Sim \\
\hline Empresa Domiciliada no Exterior & Sim & Não \\
\hline Clube/Fundo de Investimento & Sim & Não \\
\hline Sociedade Simples Pura & Sim & Não \\
\hline Sociedade Simples Limitada & Sim & Não \\
\hline Sociedade Simples em Nomes Coletivo & Sim & Não \\
\hline Sociedade Simples em Comandita Simples & Sim & Não \\
\hline Empresa Binacional & Sim & Sim \\
\hline Consórcio de Empregadores & Sim & Não \\
\hline Consórcio Simples & Sim & Não \\
\hline Serviço Notarial e Registral (Cartório) & Sim & Não \\
\hline Fundação Privada & Sim & Não \\
\hline Serviço Social Autônomo & Sim & Não \\
\hline Condomínio Edifícios & Sim & Não \\
\hline Comissão de Conciliação Prévia & Sim & Não \\
\hline Entidade de Mediação e Arbitragem & Sim & Não \\
\hline Partido Político & Sim & Não \\
\hline Entidade Sindical & Sim & Não \\
\hline Estabelecimentos, no Brasil, de Fundação ou Associação Estrangeiras & Sim & Não \\
\hline Fundação ou Associação Domiciliada no Exterior & Sim & Não \\
\hline Organização Religiosa & Sim & Não \\
\hline Comunidade Indígena & Sim & Não \\
\hline Fundo Privado & Sim & Não \\
\hline Associação Privada & Sim & Não \\
\hline Empresa Individual Imobiliária & Sim & Não \\
\hline Segurado Especial & Sim & Não \\
\hline Contribuinte Individual & Sim & Não \\
\hline Candidato a Cargo Político Eletivo & Sim & Não \\
\hline Leiloeiro & Sim & Não \\
\hline Organização Internacional & Sim & Não \\
\hline Representação Diplomática Estrangeira & Sim & Não \\
\hline Outras Instituições Extraterritoriais & Sim & Não \\
\hline
\end{tabular}




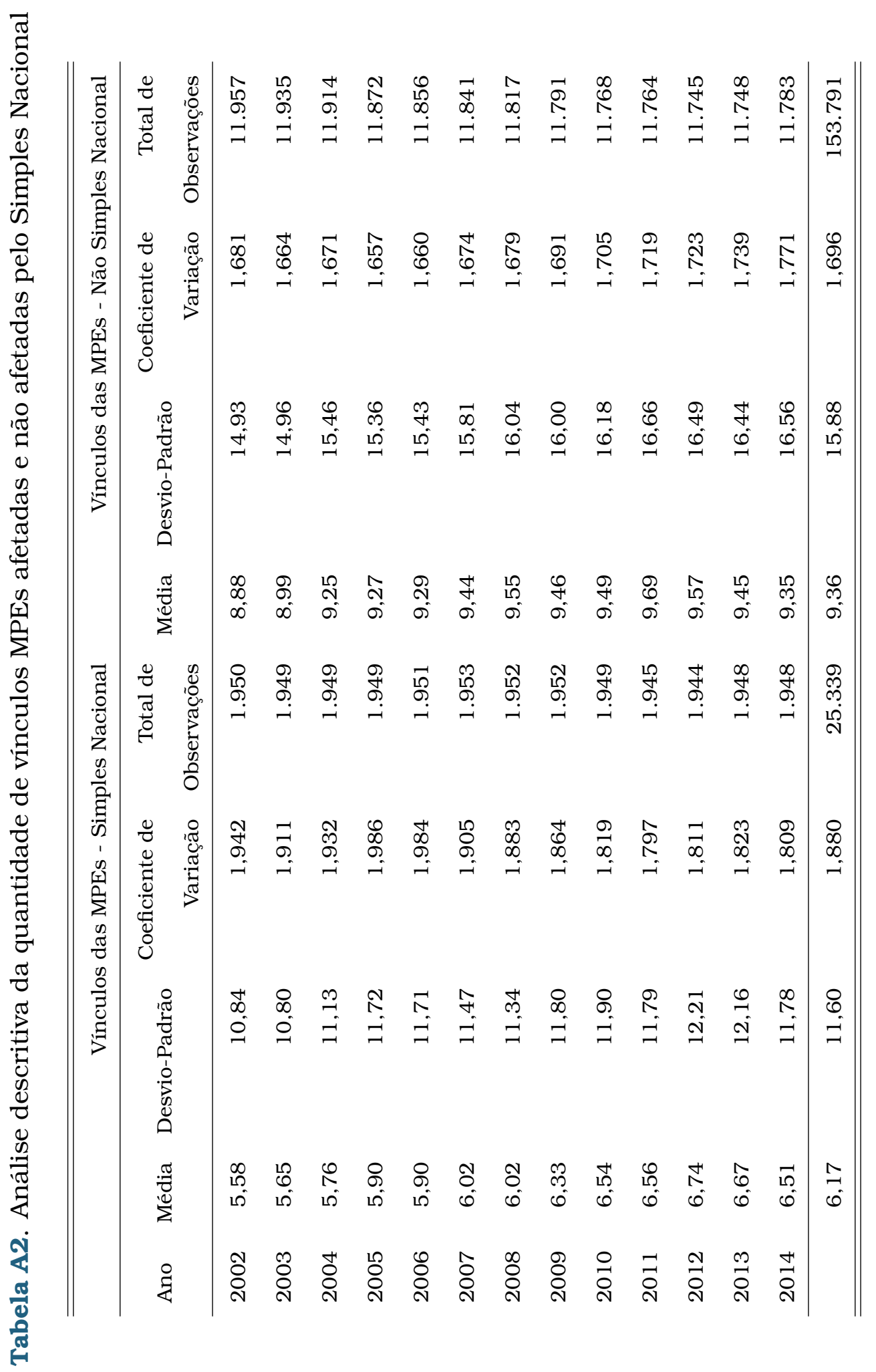


$\frac{\pi}{\vec{E}}$

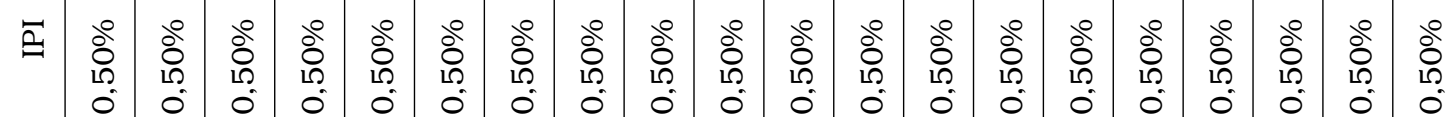

ص

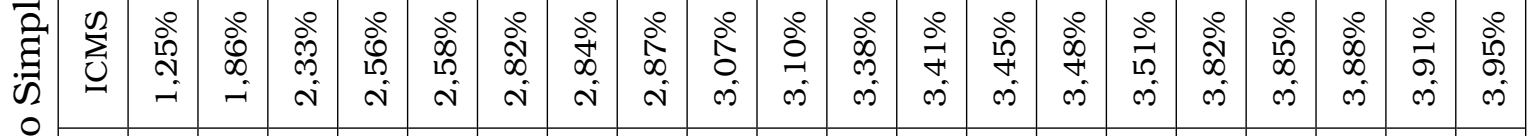

\begin{tabular}{|c|c|c|c|c|c|c|c|c|c|c|c|c|c|c|c|c|c|c|c|c|}
\hline$\stackrel{\Delta}{\Delta}$ & 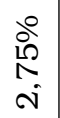 & $\begin{array}{l}\text { 今े } \\
\text { ì } \\
\text { à }\end{array}$ & $\begin{array}{l}\text { 今े } \\
\text { î } \\
\text { ì }\end{array}$ & $\begin{array}{l}\text { के } \\
\text { बे } \\
\text { ì }\end{array}$ & $\begin{array}{l}\text { ¿ें } \\
\text { ஸे }\end{array}$ & $\begin{array}{l}\stackrel{\circ}{\infty} \\
\text { N. } \\
\infty\end{array}$ & $\begin{array}{l}\text { वे } \\
\text { के } \\
\text { ஸे }\end{array}$ & $\begin{array}{l}\text { مे } \\
\text { மे } \\
\text { ஸे }\end{array}$ & 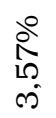 & $\begin{array}{l}\text { ते } \\
\text { రీ } \\
\text { ஸे }\end{array}$ & $\begin{array}{l}\text { oे } \\
\text { oे } \\
\text { ले }\end{array}$ & $\begin{array}{l}\text { के } \\
\text { के }\end{array}$ & $\begin{array}{l}\partial^{0} \\
\stackrel{0}{f} \\
\end{array}$ & $\begin{array}{l}\text { ○े } \\
\text { ம0 } \\
\text { +i }\end{array}$ & $\begin{array}{l}\stackrel{\circ}{0} \\
\infty \\
\dot{+}\end{array}$ & $\frac{\stackrel{\circ}{+}}{+}$ & $\begin{array}{l}\text { ᄋे } \\
\text { + } \\
\text { + }\end{array}$ & 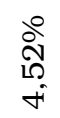 & $\begin{array}{l}\text { ठे } \\
\text { டे } \\
\text { + }\end{array}$ & $\begin{array}{l}\AA_{0}^{\circ} \\
\stackrel{+}{0}\end{array}$ \\
\hline
\end{tabular}

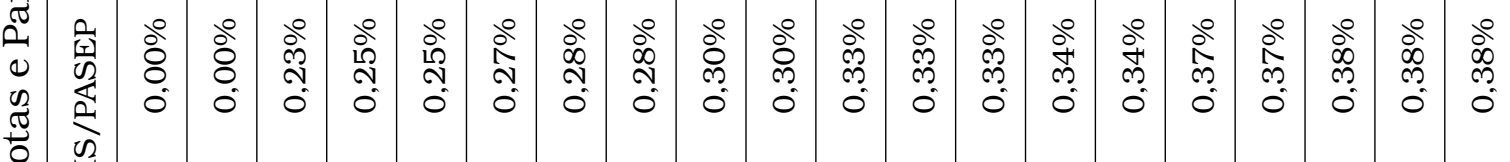

年

○

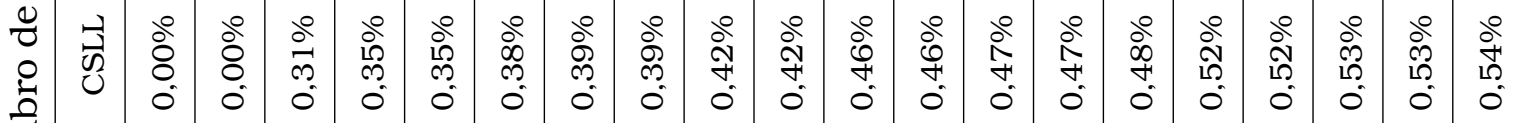

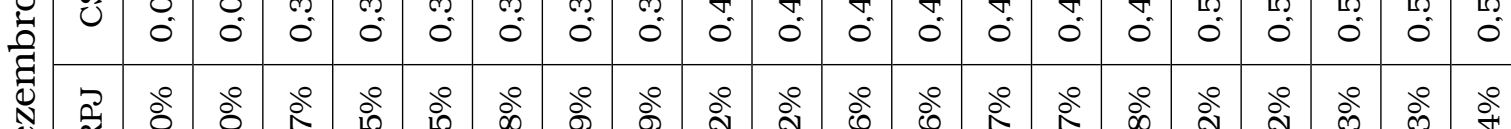

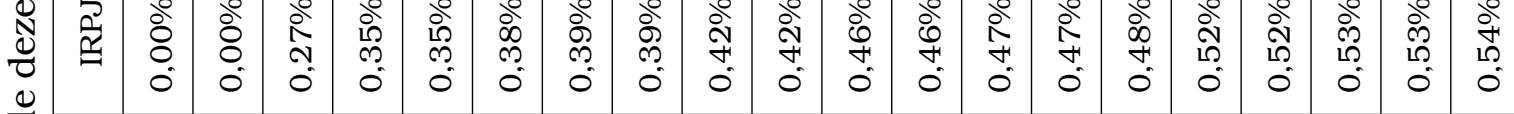

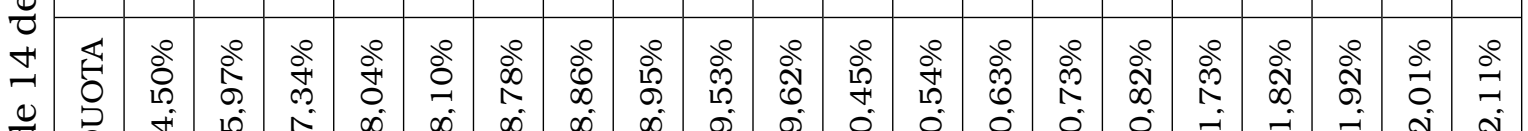

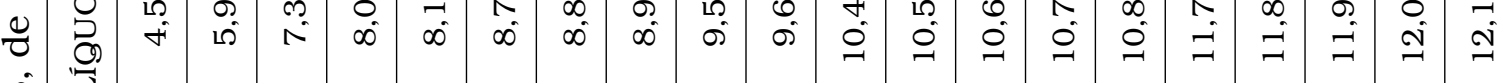

๗ิ)

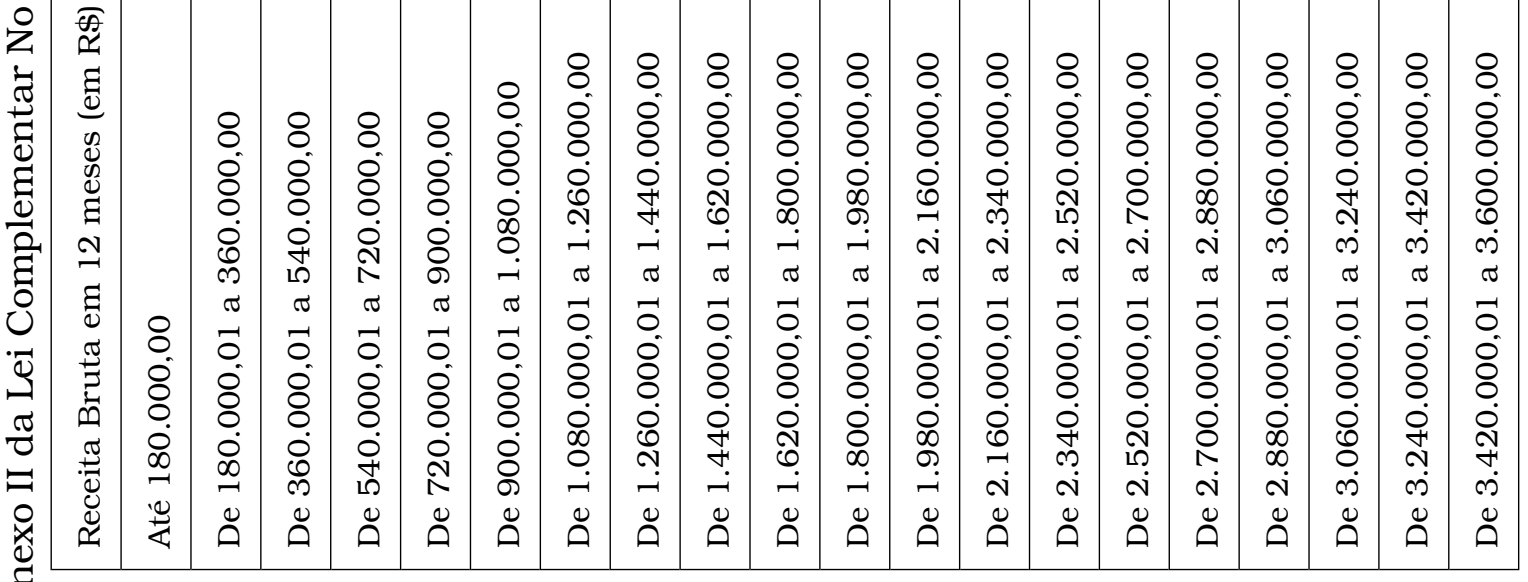

定

검 